\title{
Are coins small and boring? Developing an experiential based education programme
}

\author{
*Mieka Harris
}

\begin{abstract}
With the refurbishment of the Citi Money Gallery came the foresight to include a dedicated education programme. The collection is perfectly placed to reinvigorate financial education, which is becoming more prominent on social policy agendas. Financial education considers the local, national and international levels and is more than just creating budget sheets. It is about the appreciation of money and how to make effective decisions around it; a contextualized education programme can facilitate this. However there are numerous barriers that prevent schools from participating in financial education as well as visiting museums. This paper will consider the challenges faced by the Citi Money Gallery education programme and strategies to overcome them, including the role of object handling, creating a teacher advisory panel and investing in a pilot phase.
\end{abstract}

Keywords: Citi Money Gallery; financial education; numismatic; money

\section{Introduction}

'Coins are small and boring' (Orna-Ornstein, 2003: 96)1. This was the captured response from a child when asked by his mother if he wanted to look at a display. Obviously this is not the view held by all, but it is a challenge which any numismatic collection faces as the objects are, on the whole, small and behind glass. This means that the detail and historical content can often be underappreciated or even overlooked. The further ramification of this is the difficulty of creating an engaging education programme which teachers and students will find relevant and useful. This article will discuss findings and examples from the development of the Citi Money Gallery education programme, which aims to deliver contextualized financial education. This is a new approach to the subject and work undertaken so far has demonstrated it is a powerful method to engage students with a challenging topic. Although the Citi Money Gallery was designed to be experienced by a wider audience than just students, this article will focus on how a standard gallery space can be utilized to support educational needs. It will be based on primary research undertaken during the scoping and pilot phase of the programme, making reference to core museology concepts as appropriate. Other Citi Money Gallery initiatives do run alongside the education programme, but these will not be explored in this article.

The Citi Money Gallery was opened in June 2012 and is a permanent display, found at the top of the South stairs in the British Museum. The layout is broadly chronological, starting with the beginnings of money and moving up to the present day. Both sides of the gallery adopt a thematic approach within the cases, with the left side of the gallery focusing on the role of money with authorities and the right side with individuals. The cases in the centre of the gallery explore the making, storing and hoarding of money.

The gallery is based in the area of the former HSBC Money Gallery which, at the time of its opening in 1997, was seen as adopting a 'ground breaking vision' (Nomikou, 2011: 167). Gallery aesthetics, such as lighting, were given a key role in the design, and displays became thematic rather than purely chronological. Such strategies still form the basis of 'money museums' today, and are evident in the Ashmolean and Manchester Museum, as well as the Citi Money Gallery. 


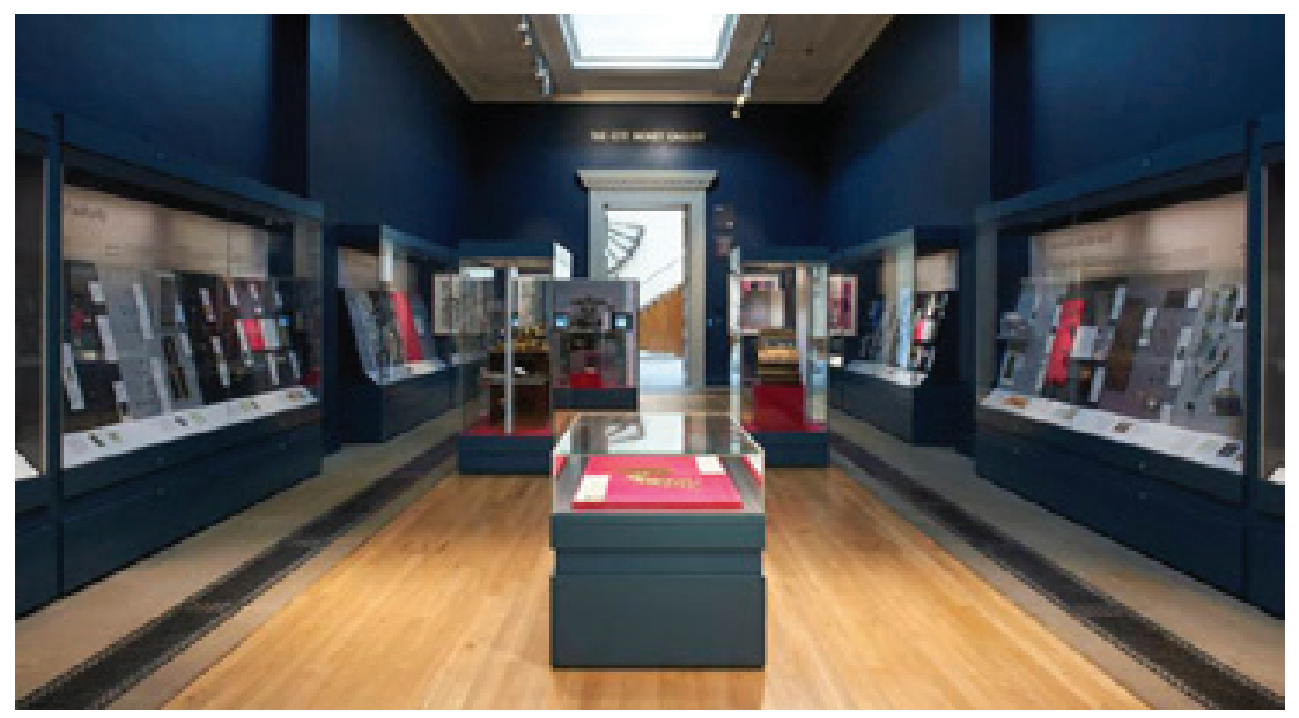

Figure 1: The Citi Money Gallery (c) The Trustees of the British Museum

\section{The education angle on a numismatic collection}

The recent global economic crisis has highlighted the need for people to have the skills to make informed financial decisions. Financial capability and achieving economic wellbeing have an established place in social policy agendas, with a shift in attitudes to prevention of poor financial situations rather than curing them. Modern society and technological developments have resulted in a change in the way money is viewed; people are exposed to financial decisions from a young age and therefore effective education is imperative. An increasing number of transactions are now online or by card with '33.1 million plastic card purchase transactions made every day in the UK in June 2014 with a total value of $£ 1.567$ billion' (The Money Charity, 20141). The resultant problem of this is a lack of awareness of expenditure and the realization that money is something tangible and finite. Numismatic collections are therefore perfectly placed to develop an appreciation of money, understanding where it has come from and how it is used.

The Citi Money Gallery offers a contextualized learning experience. It highlights that what appear to be current themes surrounding money, such as recessions, single currencies and bank accounts, have actually been experienced and evaluated over the last 4000 years. This enables learning to be placed into a wider context, and contributes to a deeper understanding of the topic. It is a truly global collection which allows financial education to be considered at the personal, local, national and international level. Avoiding learning concepts in isolation prevents students from compartmentalizing their knowledge. They can appreciate links and relationships with other areas of their understanding and, as a result, should feel more comfortable in transferring their knowledge to a variety of situations.

Experiencing subject knowledge development in a museum aligns contextualized learning with an alternative learning environment, offering a memorable learning event. By being immersed in the collection and 'interacting with the environment as the source of development, students orientate towards socially meaningful concepts and develop their capacity to think metacognitively' (Blair, 2008: 8). Such an experience cannot be replicated in the classroom, and a particularly powerful element is the opportunity students have to work with experts who are passionate about their specialism and naturally portray this. This is a unique advantage of gallery education, and such passion can act as a catalyst for student enthusiasm, and ultimately participation in the sessions. 'Learning theorists believe that, through the designed learning environments (contexts) and learning with hands-on projects, new knowledge cannot only be learned, but learned in such a way that the knowledge can be transferred for other 
applications' (Berry et al, 2005: 23). This single statement highlights a number of key areas associated with learning styles; contextualized learning, hands-on projects and the transfer of knowledge. The experiences students receive mean they will 'apply different intelligences' (Berry et al, 2005: 28) based on different learning styles. These go further than the standard visual, audial and kinaesthetic learners; as Piaget suggested (in Cardwell et al, 2004) learning occurs through discovery. Students need to be provided with activities that enable them to construct their own knowledge; this strategy will be discussed further in the article through the development of education sessions.

\section{Learning from the HSBC Money Gallery}

The then Education Service at the British Museum was part of the working committee for the development of the HSBC Money Gallery. Limited educational opportunities were created within the gallery itself, and these were evaluated alongside the gallery in 2001. The evaluation identified the location as a through route, and therefore the displays were configured to accommodate this. The heights of the cases were calculated to be accessible to small children and seated visitors, although there were slight visibility restrictions towards the tops of the displays. As a formal publication of the HSBC Money Gallery, a 'teachers pack' was produced which included classroom- and gallery-based activities. The majority of the resources were aimed at Key Stage 2 students (upper primary) and focussed on History, Art, Design and Technology, Religious Education and Geography. Gallery talks did occur, although the summary highlighted that the nature of the collection did not lend itself readily to this learning style for the students. The real focus of the education provision for the HSBC gallery was handling of the collection, highlighting that 'coins were quite literally made to be handled' (Orna-Ornstein, 2003: 97). It championed object handling within the secure environment of the museum, utilising volunteers to deliver these in the gallery. The education programme also included teaching collections for school sessions and 'money boxes' for unfacilitated use in schools, put together at little cost. These combined a small number of genuine coins with replica coins and objects alongside resources suggesting strategies for their use in the classroom. The plan was that the boxes would be loaned to schools for a six week period; however, the logistics of getting these returned to the museum were problematic. Various costs were involved, systems had to be developed for those returning the boxes late and refreshment rates to the boxes were relatively high, making them a very time-intensive resource from a museum perspective.

\section{Challenges of the Citi Money Gallery}

Although a gallery refurbishment occurred, a number of the key structures in the gallery remained the same, including the locations and dimensions of the majority of the display cases. As mentioned, there had been a small primary education programme with the HSBC gallery; the new Citi Money Gallery has a dedicated education role with a focus on secondary students. Some resources were available from the previous programme, although these were mainly designed to be used unfacilitated or offsite. The majority were quite generic in their approach and many had a primary-level focus. Although some concepts and ideas were transferrable, the new programme would be aimed at secondary school students and therefore would need to target subjects and learning outcomes more specifically. Effectively then, the programme had to be designed from scratch. Alongside this, as mentioned already, a lot of the previous education work was with primary schools, and so there was no existing secondary schools network for the programme to utilize.

Not only did a new programme have to be created but it would need to be integrated alongside established programmes in the field. Aligning the programme with the gallery collection does provide a 'unique selling point', offering a different perspective on the delivery of financial education. With the focus for the programme on financial education, it was a completely new area for the museum. The British Museum is established in the sessions offered relating to other curricular subjects, such as history and art, but it is arguably not an obvious setting for financial education. Therefore the existence and profile of the gallery and the education programme had to be developed simultaneously with the creation of the programme; for one to happen before the other would have not made sense given the time-lags within the education 
sector. However, there was very little existing web presence and almost no marketing initiatives specific to the education programme, and so these would need to be incorporated into the design of the programme.

The collection itself has already been identified as a challenge, given the object sizes and their positioning behind glass. The layout of the gallery also poses difficulties; it is long and thin and therefore does not easily accommodate large groups. As it is a public gallery, groups of school students need to use it alongside members of the public. It could also be viewed as a 'corridor' from the top of the South stairs to the other galleries and exhibits. This means it is often busy with through-traffic.

The final main challenge with this programme is that financial education is not a statutory subject in England. Despite numerous entities and organizations recognizing its importance, many schools do not participate in it or incorporate it into their teaching. From September 2014 , it has been on the national curriculum within mathematics and citizenship. Whilst museum education programmes should not feel the need to be fully aligned with the National Curriculum, particularly with the rise of academies, schools do have to justify students' time at the museum. If financial education remains on the 'wish list' rather than a statutory objective that the school will be measured against, then committing time to it, particularly in the format of an excursion, will fall down the list of priorities.

\section{Strategies to overcome the challenges}

\section{Aligning with existing initiatives}

The initial stage of the programme involved an intense phase of scoping and identifying best practise from organizations including The Royal Mint Museum, The Museum on the Mound, The Bank of England Museum, pfeg and The Money Charity, among others. This enabled a clear framework for the future development of the programme to be created, highlighting existing provisions and strengths of complementary organizations. A network of contacts was formed to ensure that the Citi Money Gallery education programme was not being developed in isolation, nor replicating an established scheme.

As well as working with the existing provisions at the British Museum, opportunities were identified during the scoping phase to support external initiatives related to financial education. For example, the National Association for Student Money Advisers hosts National Student Money Week in February each year, and Global Money Week is organized each March by Child and Youth Finance International. These enabled the education programme to be put into context and provided an instant promotional platform. Bespoke activities were created for each initiative, and therefore schools participated in a collaborative session between the organizing institution and the Citi Money Gallery. To further raise awareness of the programme to schools, existing schemes and projects were also approached for collaboration. One such example of this was the Institute of Mathematics and its Applications annual competition, which last year was run in conjunction with the Citi Money Gallery. Students were asked to design a coin for the planet Earth, taking inspiration from the gallery and the associated website, and include technical specifications to ensure the mathematical element was addressed. This has been another successful strategy to raise the profile of the financial education programme available at the British Museum and engage students with the collection.

Aligning with existing organizations and initiatives strengthens the role of the education programme, as it enables teachers to appreciate that it is a complement to existing work in the field. Such strategies also provide immediate engagement with existing networks, increasing the profile of the Citi Money Gallery education programme.

\section{Engaging with the education sector}

Much of the information gathered through the scoping phase was third party information, and therefore a teacher advisory panel was also established to provide an interface with the endusers of the sessions and resources, rather than making assumptions about their requirements. Schools that the British Museum has worked with in the past, as well as local schools, were 


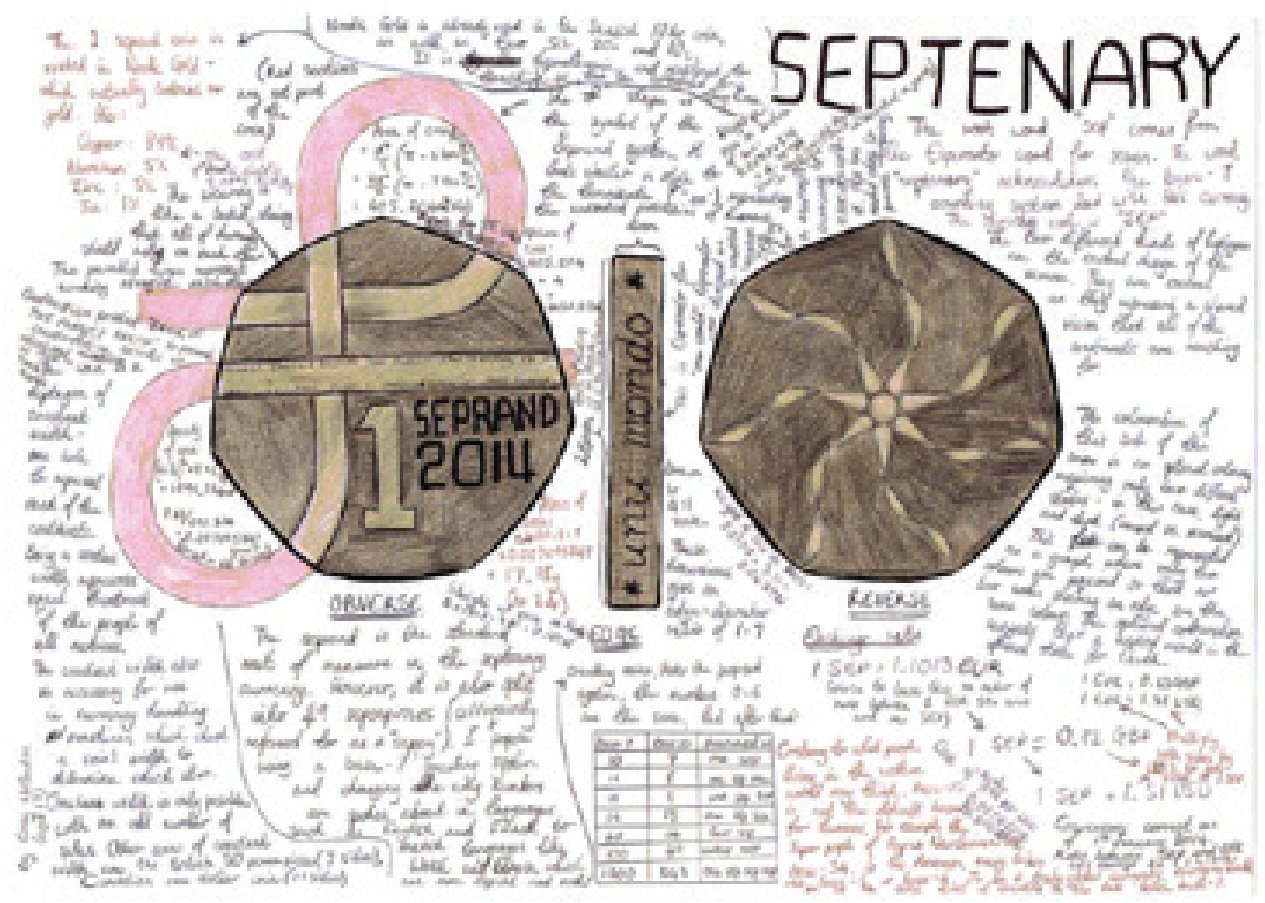

Figure 2: Winning entrant in the age 17-19 category @ The Trustees of the British Museum

invited to attend the initial meeting. As a result, seven teachers meet once a term to discuss the programme. There are representatives from the mathematics, economics, business studies and citizenship curriculum areas, ensuring a robust and cross-curricular set of opinions. The panel meetings are structured sessions, enabling teachers to share their views around key themes for the programme. Teachers have responded very positively to being involved in this process, appreciating that their knowledge and experience is being utilized for the benefit of a wider audience. As a result, the Citi Money Gallery programme has teachers and their students at its core, adopting a grassroots approach. The panel has also acted as a sounding board for ideas to be formed, knowing that practising teachers currently working within curriculum frameworks would provide honest and realistic feedback. This has been, and will continue to be, invaluable. It also adds validity to the programme; other schools will recognize the contribution made by their peers and professional colleagues, entrusting their judgement and endorsement of the resources. Not only have the teacher advisory panel been able to offer an insight into the content of the resources, but they have also advised on the format of the sessions and the logistics of a school excursion.

A relatively simple statement came through a panel meeting, yet it is one which is fundamental to the programme; 'it needs to be something that can't be replicated in the classroom'. Assumptions may be made that teachers and students prefer a certain format, but actually the desire is to experience something different. Modern educational psychology often refers to the triadic interplay in reciprocal determinism between behaviour, personal and environment, with the latter being directly linked to context (Thompson, 2008). The education programme therefore offers contextualized learning which may build on prior knowledge but offers an alternative setting to develop this.

The involvement of teachers provides a sense of validation to the programme, which speaks volumes to fellow teachers who often have a very limited amount of time to interpret and trial new resources. Therefore word-of-mouth or recommendations will be appreciated 
by those working in secondary education and so it is important that the contributions from teachers and students are recognized in the resources.

\section{Creating a pilot phase}

Although consultation had occurred with teachers, it was important to pilot the sessions and resources with students in order to evaluate the tasks and appreciate the logistics involved, particularly when using small objects such as coins in a classroom-setting. This was a twostage process, and the strong relationships established through the teacher advisory panel enabled the pilot material to be tested first in school during a normal lesson. Experiencing the materials in a familiar environment was a particular benefit to the programme, allowing student evaluations to be specific to the session rather than this being an add-on to a museum visit. Working with small groups using targeted material made it easier to appraise their responses, which often took the form of non-verbal communication or informal conversations with their peers. From experience, we know that once students have to commit their feedback to paper, the initial reactions to the materials can be lost. Written feedback can also result in short, non-descript answers which may not portray an accurate account of the event. Therefore as well as taking field notes during the pilot sessions to capture responses as they occurred, structured evaluation activities were also implemented at the end of the session. This was complemented with a follow-up session led by the class teacher without any museum staff being present; returning students completely to their familiar environment, allowing them to relax and provide honest feedback. After the initial pilots within schools, classes were invited to attend sessions at the museum. This provided the opportunity to incorporate suggestions identified in the evaluations and re-run the activities, with the additional element of an unfamiliar environment. It also enabled the logistics of the session to be determined, including travelling between the British Museum's Clore Centre for Education and the Citi Money Gallery, which involves two sets of stairs and a four minute walk.

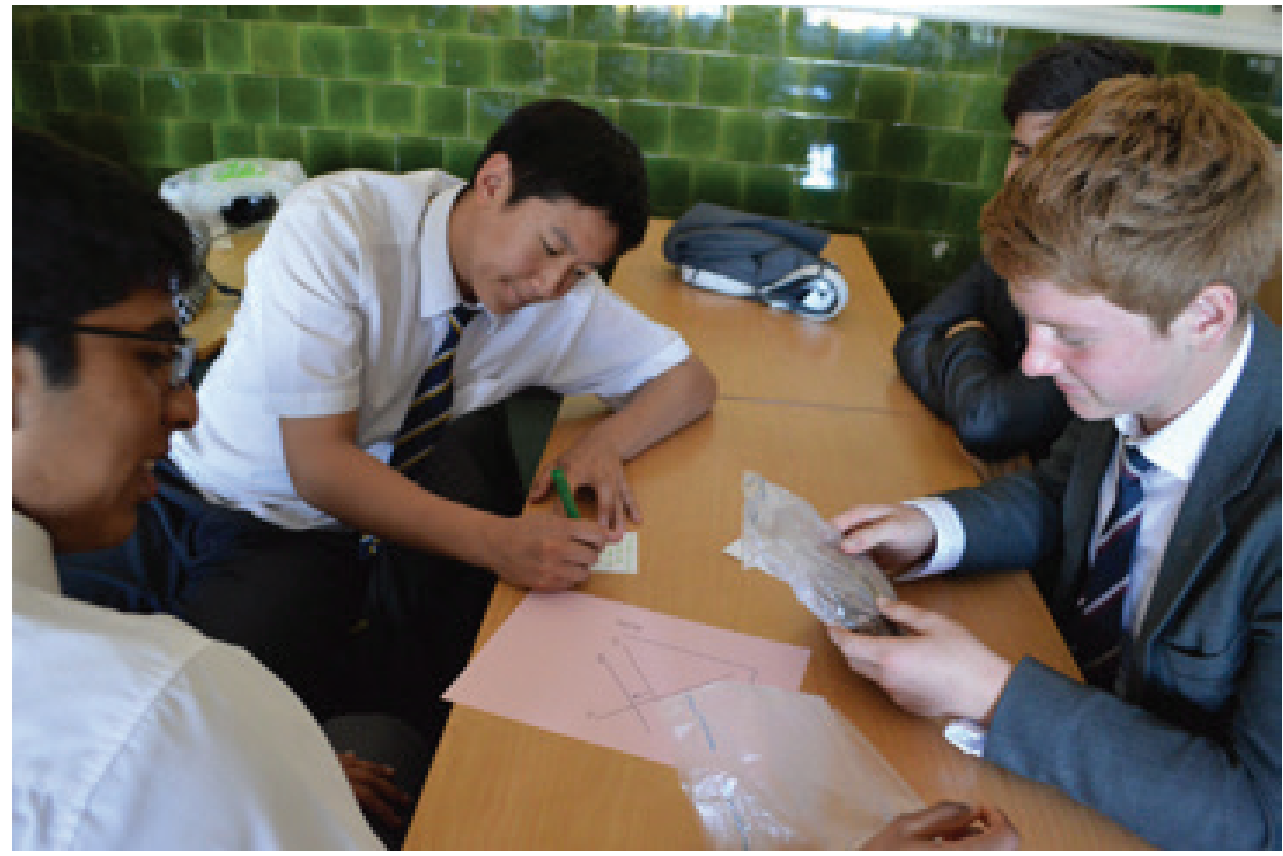

Figure 3: Students participating in the pilot phase at Reading School

Photograph: Benedict Johnson (c) The Trustees of the British Museum 
further outcome of the pilot was the creation of a student advisory panel with a small group of sixth-form students. They collaborated on the development of a KS4 economics resource alongside sharing their experiences and insights relating to the programme. In order to recognize the commitment of this group, skills-based sessions were incorporated into their panel meetings. These included curriculum vitae and application form planning and interview preparation, as well as understanding the various roles available in the museum sector.

Allocating time to a pilot phase ensures that there is a strong cohesion between the objectives of the museum session and the requirements of the education sector. This enables the entire session time be used effectively, which is appreciated by teachers and should increase the possibility of a repeat visit.

\section{Using object handling and enquiry-based learning}

The use of manipulatives has always been prominent in promoting student understanding, enabling kinaesthetic connections to be made with learning. The role of object handling is well documented in museum education literature; a detailed discussion is beyond the realms of this article, although a few key themes will be referenced. A study into object-based learning found that 'hands-on activities led to improved outcomes for pupils and students, including better achievement, standards, motivation, personal development and behaviour' (Ofsted, 2008). Object handling therefore plays a prominent role in each Citi Money Gallery education session, regardless of the age of the students. It is a unique opportunity for the students to interact with original artefacts, and they appreciate the responsibility placed in them partaking in it. By doing this, learning can be associated with imagery and feelings; these associations support the development of a longer term memory as 'a session that has a memorable "hook"

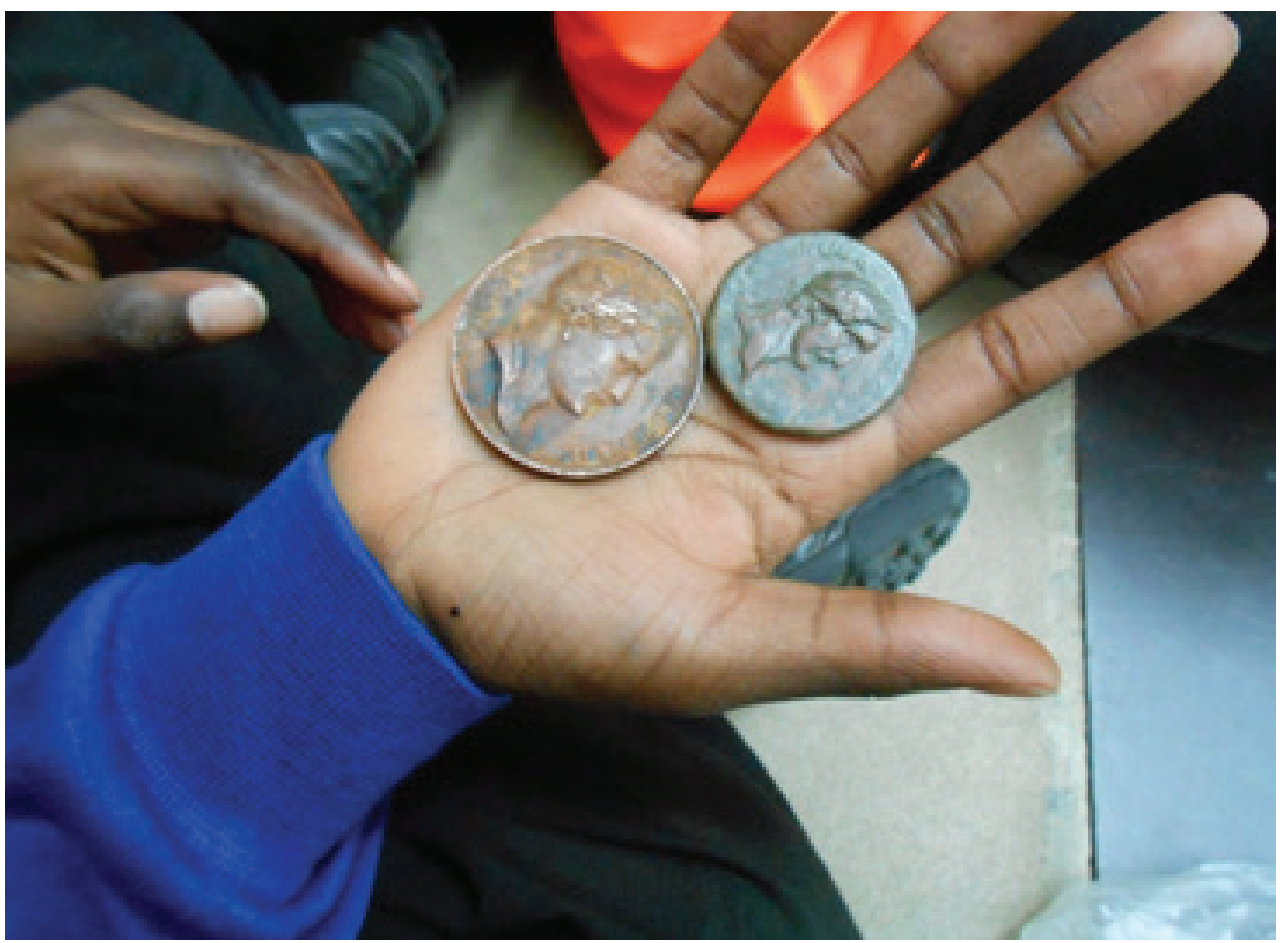

Figure 4: Student handling objects from the collection Photograph: Benedict Johnson (c) The Trustees of the British Museum 
to it is more likely to be retained by the student' (Hardy, 2008: 29). Object handling therefore creates learning experiences that optimize understanding and application. They also provide students with the opportunities to think both divergently and creatively, being able to consider different lines of thought for a single artefact.

Arguably then, synonymous with object handling is enquiry-based learning. The Citi Money Gallery itself does not immediately align to financial education, but inspiration can be drawn from the objects in the collection. Through analyzing objects, students can follow a number of lines of enquiry, which also promotes independent learning. Students will often enjoy this freedom to develop their own understanding, although some may require the learning to be scaffolded in order to support them in reaching a position where they are able to create their own enquiry questions. Learning through discovery enables students to construct their own knowledge through the process of accommodation. Rather than knowledge being accepted as a surface level fact, as can happen in passive learning, by enquiry learning students evaluate and link ideas to existing thoughts. Arguably the knowledge progression is much deeper in this format as students have the opportunity to create new internal knowledge structures (Rebello et al, 2007). It is also essential that prior knowledge around a topic is considered. This will ensure that the understanding developed through experiences and enquiries can be related to existing thoughts, supporting the dynamic continuum of knowledge development. Enquirybased learning is therefore fundamental to all Citi Money Gallery sessions. Through the use of objects, students are encouraged to explore the historical and modern concepts related to them. This is then used as the basis to develop learning throughout the session.

Incorporating these long standing strategies into the structure of an education session ensures they are engaging for students. It also supports the notion that museum sessions offer something different to the classroom experience and therefore are a valid investment of student time.

\section{Seeing the space as an alternative learning environment}

The structure of the enquiry-based learning continuum is important, not only to connect with existing knowledge, but also to ensure the new learning can be transferred to various situations. This relates to the vertical transfer of knowledge, which can be more difficult for students to engage with but is crucial for the ability to apply existing knowledge in unfamiliar scenarios (Rebello et al, 2007). To support this, students need opportunities to think creatively and the freedom to enquire. It can be difficult to offer such things in a classroom setting which students use on a regular basis. Therefore the move to an alternative learning environment with different experiences can certainly offer these opportunities; again this ability to offer something that cannot be replicated in the classroom is promoted in the education programme.

Providing situations for students to be more creative also enables them to develop their Key Processes, common to mathematics and science but utilized in most subjects. These are skills that sit outside the constraints of a subject-specific curriculum but are crucial to the successful application of curriculum content. Key processes are mainly verbs and therefore the learning of them comes through doing them; for example 'analyzing' and 'reasoning' are key processes, but the learning of such skills cannot be delivered in the same way as solving linear equations. With many subjects becoming more functional in their assessments, it is imperative that students have numerous opportunities to practise these skills. However, attempting to recreate a real scenario in a classroom often results in an artificial situation, with which students struggle to engage. Functional Skills qualifications have been in place in the UK since 2012, replacing various similar initiatives. The aim is to raise the level of literacy, numeracy and ICT amongst students; however, the assessment is the ability to select the appropriate knowledge and apply it to a situation. Whilst teachers can facilitate the learning of this 'knowledge', supporting students to understand how to transfer it is more difficult. The assessment situations are unpredictable and, therefore, whilst similar scenarios can be reviewed, students will ultimately face an unfamiliar problem in order to emulate real life. Therefore the main way to appreciate when and how to apply existing knowledge is to experience as many 'situations' as possible. Museum education is therefore perfectly placed to support this as, although they are still artificial situations, the unfamiliar environment and unknown people create the appearance of a more realistic scenario. 
Museums and galleries make influential alternative learning environments, enabling a more creative and holistic educational experience to occur. Empson (1932) alludes to this in his Homage to the British Museum; 'Attending there let us absorb the culture of nations, And dissolve into our judgement all their codes'. Again, the literature on learning outside the classroom is vast, and the advantages to it are numerous, however the overarching benefit is the longitudinal effect;

These, often the most memorable learning experiences, help us to make sense of the world around us by making links between feelings and learning. They stay with us into adulthood and affect our behaviour, lifestyle and work. They influence our values and the decisions we make. They allow us to transfer learning experienced outside to the classroom and vice versa.

\section{(Learning Outside the Classroom manifesto, 2011)}

Watson (in Harris and Butterworth, 2004) emphasized the importance of experiences to support development, enabling children to relate their new knowledge to either existing thoughts or a linked environment. Therefore, the environment is very much part of the education session, and in fact enhances it. It provides a platform to which associations and memories can be linked, enabling students to draw on their experiences long past the actual event.

\section{Maximizing the outcomes from a school visit}

Attending a museum session is an investment of time for the students, and therefore will need to be justified within school management systems by the teachers. The teacher advisory panel suggest that this is more of a challenge for secondary schools than primary, as time constraints are faced given the curriculum content requirements and national assessments. There is also the issue that not being in school for one day in secondary schools impacts more than one teacher and subject, and so agreement for a single trip needs to be sought from a number of departments. Validating this time off school sites is made easier if there are multiple outcomes from a school visit. Although the trip may be based around a single subject or learning point linked with financial education, it is important to highlight all the benefits of visiting a museum. The main one arguably is the cultural element; this falls under the umbrella of Spiritual, Moral, Social and Cultural development of students, as identified by the Department for Education. Cross-curricular links through the delivered museum session should also be made evident, supporting students in decompartmentalizing their learning and promoting the development of Key Processes.

Furthermore, the school visit should not be viewed as an isolated and advantageous day out of the norm, but an integral part in the students' knowledge development. By being aware of the outcomes from the Citi Money Gallery education sessions, teachers should be able to include the excursion within a unit of work. To help facilitate this, pre- and post-visit material is supplied to set the trip in context. This also helps form links between classroom learning and the opportunities at the museum. However, as alluded to earlier, severe pressure upon time is a very prominent factor in teacher decisions. This has been particularly noticed within the financial education area, as it is a non-statutory subject. However by providing starter activities and short resources available on the website, teachers are more able to implement these within a lesson rather than having to dedicate a whole lesson to it. Numerous curriculum topic areas can be linked with financial education and so strategies are available to teachers to emphasize the connections between it and subject-specific items. For example, compound interest in mathematics can be related to saving strategies, as can ration situations in history. Little time is required to highlight these links, but it means both the teacher and student are able to engage with financial education.

However, it is also important to accommodate those groups that do not have easy access to the British Museum, and so outreach work has also been trialled. Again, object handling has been a prominent feature; this has been part of a taught session rather than sending a handling box and guidance notes, as per the format in the HSBC Money Gallery education programme. By working with students and schools through this model, the Citi Money Gallery 
gives them the opportunity to engage with and experience some of the collection. This can also have a reciprocal outcome, where the outreach work is incorporated into the onsite programme as exemplary work for other school groups. The other possibility is to create a display in the museum, as was the result of a project with Great Ormond Street Hospital School. The teacher advisory panel commented that confidence in taking schools groups offsite may be a barrier and therefore this is one strategy to help address this challenge. Teacher training sessions on 'planning a visit to the museum' are already established at the British Museum, and the Citi Money Gallery is also promoting the value of this tool to teachers.

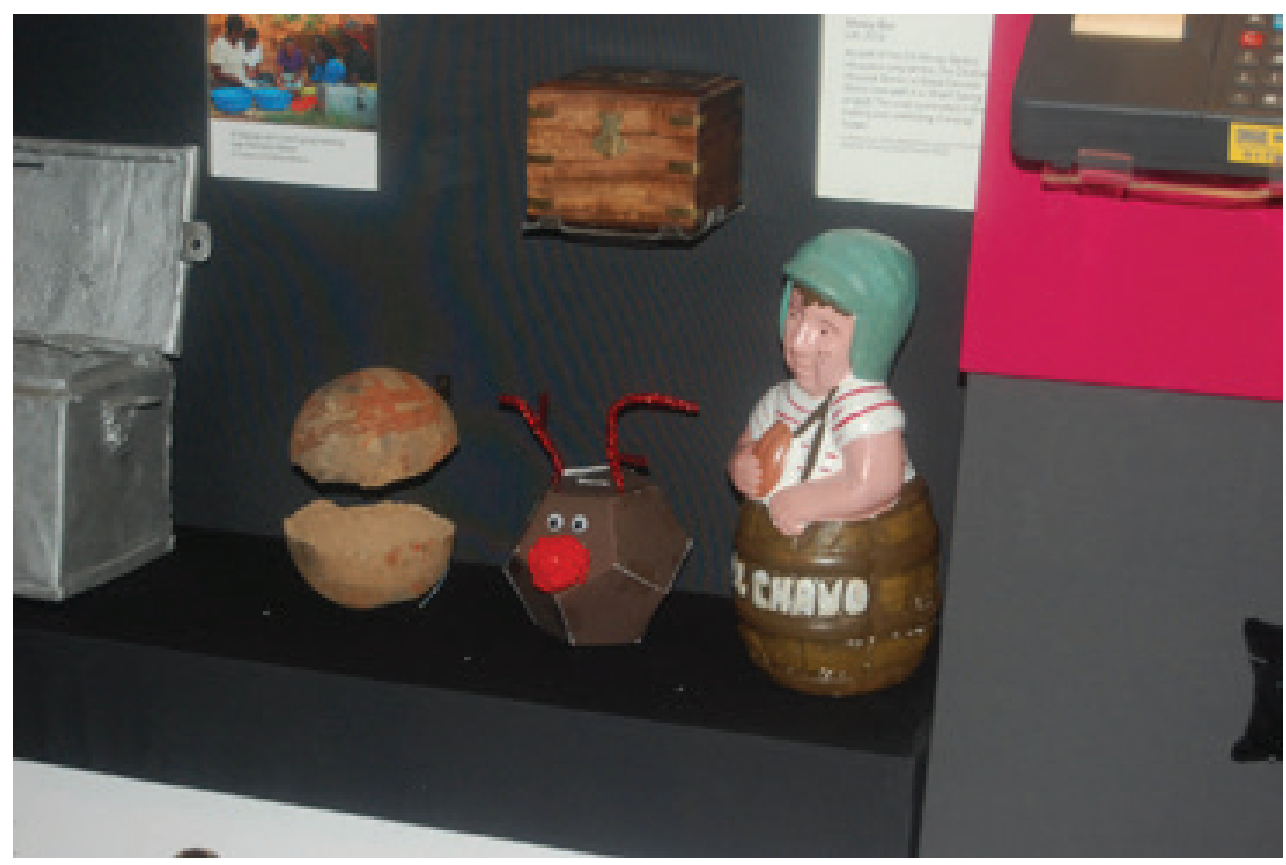

Figure 5: A money box from the Smart Savings project with Great Ormond Street Hospital School on display in the Citi Money Gallery (C) The Trustees of the British Museum

It is important that all the outcomes from a museum visit are shared with teachers to ensure they realize the opportunities available to the students. This will help them in their case to senior management teams to support the visit and justify that a day away from the timetabled curriculum is a valuable investment of time.

\section{Contextualized financial education: Case study of 'Stash the cash, Splash the cash'}

A common theme in financial education is budgeting and the teacher advisory panel informed that this often fell to the mathematics department to deliver on collapsed timetable or extended curriculum days. Budgets do appear in the citizenship curriculum, but extrapolating these back to personal budgeting techniques is not always evident to students. Therefore this area was identified as being of use to teachers and so further discussions took place with teachers and students as to possible session objectives.

When developing the session it was important to keep in mind that inspiration should be drawn from the collection. This also enables it to be a unique learning opportunity as well as being something different to both classroom activities and other materials already available in the education field. Therefore, the themes behind this session are to explore the concept of value, consider the notions of saving and understand priorities when allocating budgets. The REACT theory for teaching and learning was also employed; Relating, Experiencing, 
Applying, Co-operating and Transferring (Berry et al, 2005). These five activities are identified as 'contextual learning strategies' and act as guidelines for creating learning experiences that optimise understanding and application. Students start with an activity trading common modern items to develop an understanding of comparative values and the idea that the assigned value may depend on current needs. There is then a move to the Citi Money Gallery to explore hoards and identify objects discovered within them. The discussion around hoarding is then furthered back in the education room, exploring the terms 'valuable' and 'precious' as well as questioning whether all things that are valuable can be hoarded. Throughout this section, parallels are drawn to modern day saving reasons and techniques. Students then participate in object handling to appreciate how money and coins have developed. From this, students are given a hoard of Roman coins and asked to identify the monthly needs of a Roman family and allocate an amount to each need. The hoard value is then converted to a modern monthly budget equivalent and students consider any differences in needs and look at actual costings of items. These should elicit the idea of distinguishing between needs and wants and that the premise of a budget is proportionately assigning amounts. With the underlying concepts being developed through a variety of contexts, these skills are then transferrable to future unfamiliar situations.

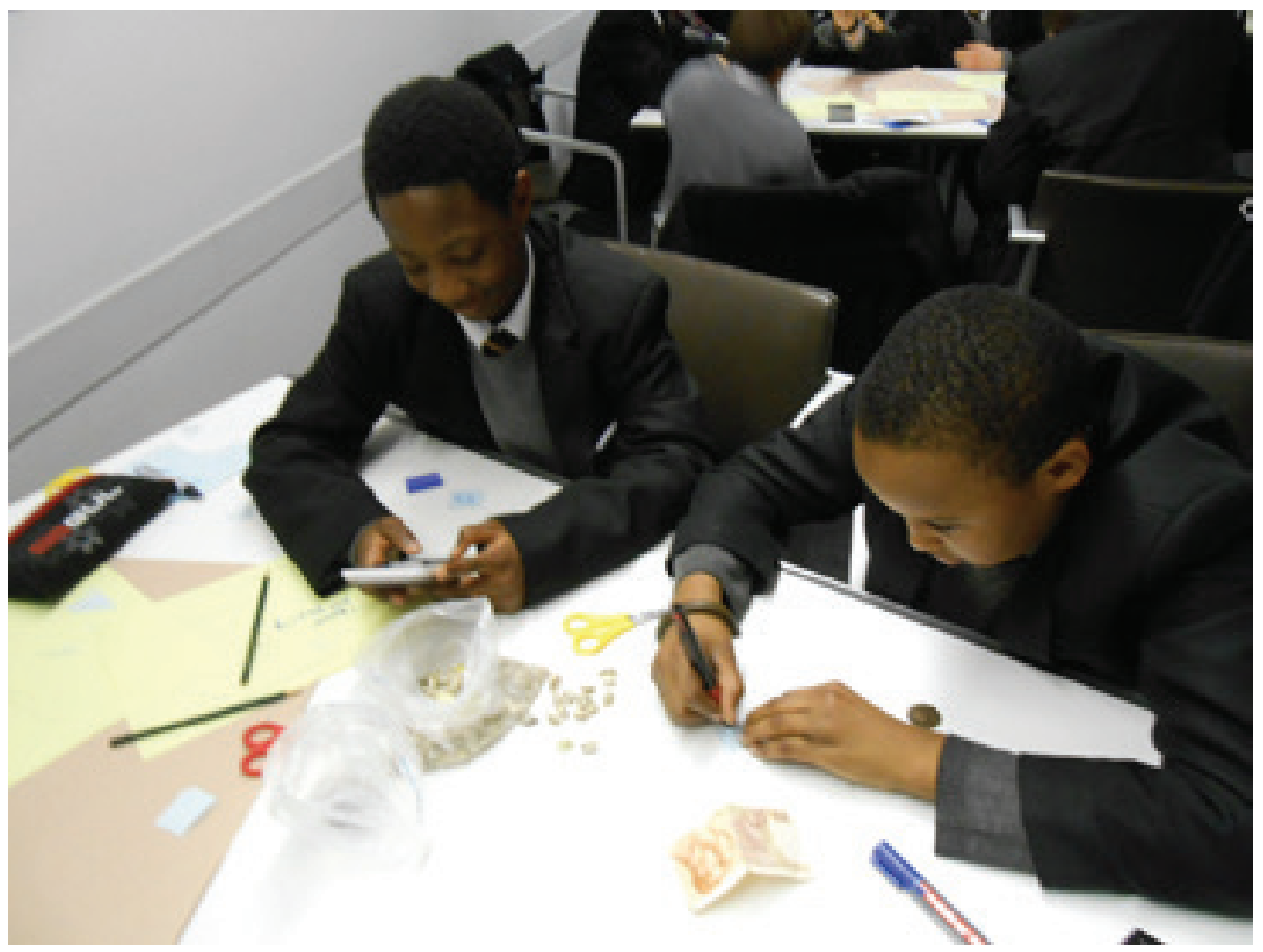

Figure 6: Students working on creating budgets

Photograph: Benedict Johnson (c) The Trustees of the British Museum

Throughout the session, therefore, learning outcomes are continually matched against objects or themes from the collection. The session was piloted with a KS3 group of students from a local secondary school, providing an opportunity for both the material and logistics to be tested. Students and teachers attending were invited to take part in a rigorous evaluation of the session, from which some key areas for improvement were identified. These revisions were made before the session was incorporated into the published programme. 


\section{Outcomes and future plans}

From September 2014, there will be a full bookable programme available to schools at the British Museum. Based on the pilot phase outlined in this paper, this will include a variety of activities addressing different learning styles and needs. For the onsite schools sessions there will be a fixed number of options to select from, providing a happy interim between the programme being too generic and being responsive; these include Stash the cash, Splash the cash (KS3 mathematics); Dicker, barter, deal, trade (KS4 economics) and Budge-it budgets (KS3 and KS4 citizenship). Through the teacher advisory panel it became apparent that for schools investing time in a visit, the outcomes needed to be worthwhile and multiple. Therefore the onsite sessions will include financial capability activities in the morning, addressing areas of citizenship and PHSE. The afternoon session will continue with the theme of financial education but it will be delivered in the context of a subject. For example, art would consider banknote designs and the portrayal of wealth in art; geography would look at the financial impact of natural disasters and so on. There will be provisions for mathematics, economics, business studies, art, citizenship, English, drama, geography and history as well as a cross-curricular session being available. All sessions will include object handling and a visit to the Citi Money Gallery, providing a cultural and spatial aspect to the trip. Therefore by participating in a single excursion, students will have numerous experiences in order to help validate the time away from timetabled lessons. Alongside these sessions, the programme will also include study days, allowing an area to be considered in detail. These will be aimed at sixth form students and adopt a lecture format with break-out seminar sessions, providing an insight into the learning style often provided at university. Unfacilitated resources will also be available, allowing teachers to use the galleries without a museum member of staff needing to be present. The variety of options should enable a number of schools to participate in the programme at some level, and outreach work will continue to feature alongside these.

To complement the onsite sessions, a comprehensive website has been created. This captures all the opportunities available to schools and provides pre- and post-visit material for additional support. It also includes resources inspired by the collection that teachers can use in the classroom. Following a discussion in the teacher advisory panel, it was recommended that resources should be succinct (maximum of two pages) with the intended learning outcomes clearly stated at the start. Therefore this format has been adopted throughout, enabling teachers to see at a glance whether the resource is appropriate. The resources also include curriculum links to ensure they can be incorporated into a unit of work, although they can be used as stand-alone or enrichment activities. The website also promotes the latest collaborative project or competition; these updates are included in the wider schools e-newsletter distributed by the British Museum as well.

The programme formally launched in March 2014 with a financial education conference entitled 'Why are sweets by the till? Delivering empowering financial education', with Martin Lewis from moneysavingexpert.com as the guest speaker. This was a free event for educators currently participating or with an interest in the role of financial capability, with the key aim being to provide delegates with models and strategies for delivering it. The conference brought together a number of charitable institutions and organizations involved in supporting schools with financial education, and it is believed that this is the first time in England such an event has occurred. With elements of financial education being compulsory in the National Curriculum from September 2014, the conference was extremely well attended. It was a great opportunity for teachers to experience the sharing of best practice and a chance to appreciate that the use of museum collections and resources are excellent starting points for reinvigorating financial education.

Through the conference and the teacher advisory panel, it has become apparent that those often delivering financial education do not have subject-specialist knowledge in this field, which can affect their confidence levels in teaching it. The teaching profession is one of continual learning and teachers are interested in initiatives that offer career professional development. Therefore there are future plans to provide teacher training in delivering effective financial education. However time constraints remain an issue for practising teachers, and so engaging with initial teacher training is also a field being developed. Trainee teachers are keen to explore various ways of delivering curriculum content and therefore before they are in 
a full time teaching post is the perfect opportunity to sow the seed of using museum collection environments as an alternative learning space. The other advantage to this is that on completion of their teacher training course, the trainees will work in numerous different schools, spreading the network of teachers that are aware of the education programme. Pilot sessions have been undertaken with three teacher training institutions, with students spending an enhancement day at the museum focusing on financial education strategies and the wider role objects can play in supporting their teaching.

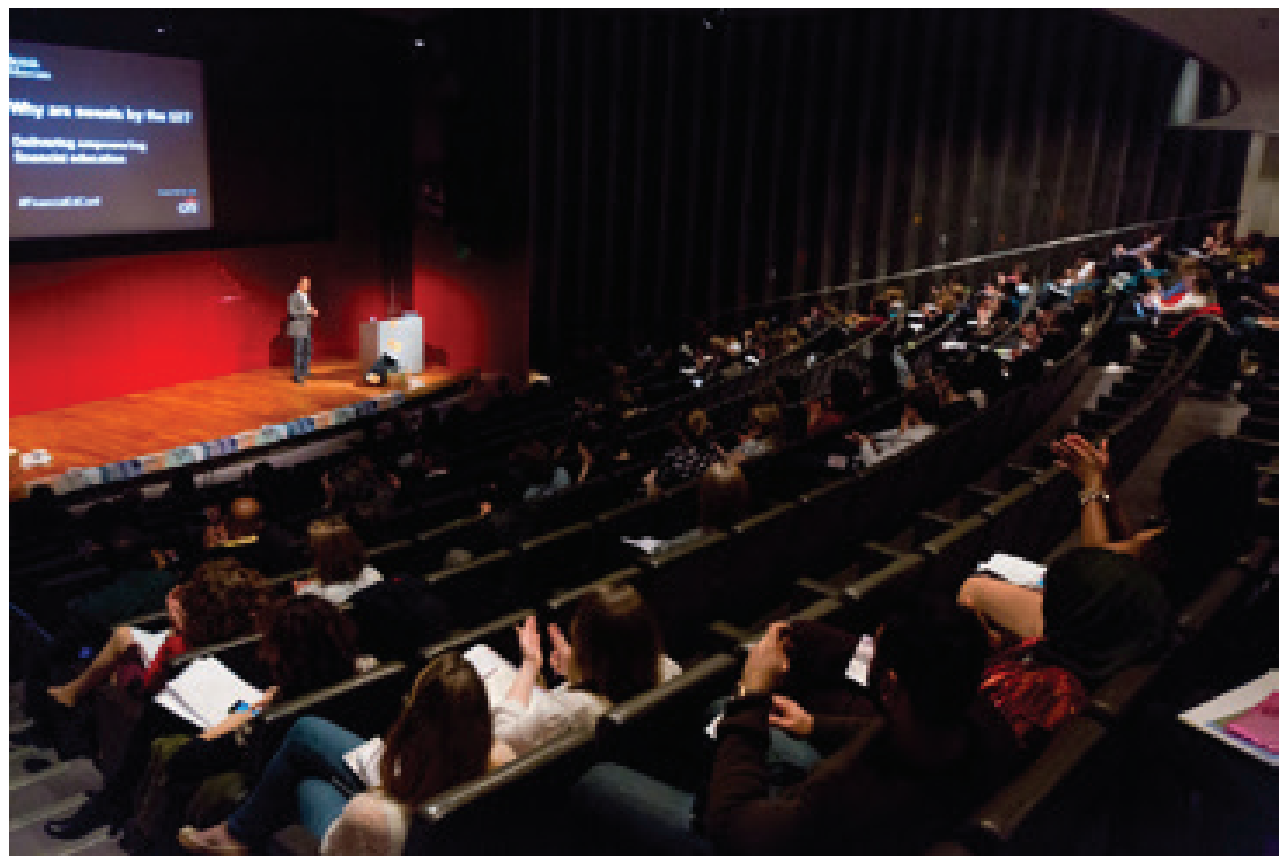

Figure 7: Martin Lewis speaking at the financial education conference 'Why are sweets by the till?' Photograph: Benedict Johnson (c) The Trustees of the British Museum

\section{Conclusion}

Museums and galleries make influential alternative learning environments, enabling a more creative and holistic educational experience to occur. They are effective tools for enriching classroom-based learning and provide unique opportunities to students. However it is important to involve and engage teachers in any programme so that they are fully aware of these possibilities and can participate in them. Although concluding thoughts in relevant sections in the article and these closing comments focus on the numismatic collection in the Citi Money Gallery, parallels can be drawn to other museum collections.

In this case, a gallery refurbishment was the stimulus for readdressing the education programme, although the actual changes to the structure of the space were limited. Therefore time spent during the scoping phase of re-examining and understanding the Citi Money Gallery space was highly beneficial to reinvigorating its use as a teaching space. During this time, it was also imperative that museum objectives for the programme were aligned with those in the education sector; teachers have a very limited amount of spare capacity to explore new opportunities and if they cannot immediately see the advantages to their students then sessions and resources will often get overlooked. Targeted material using education language and buzzwords is therefore imperative.

In developing the Citi Money Gallery education programme, time was also invested in the pilot phase. This enabled a true understanding of the field to be developed, making it easier to identify the education areas which the programme could support. As discussed earlier, it 
was important that teachers did not see this initiative as 'another new idea' which they would need to consider but rather as a complement to existing programmes. This also strengthened the understanding that the 'wheel' was not being redeveloped but rather being given some different 'spokes' to support its role in the wider objective of financially educating students.

The engagement of teachers and students in the pilot phase provided another dimension to the programme. It enabled it to adopt a grassroots approach and evolve in response to session outcomes. Money can be a sensitive issue to discuss and work with, however, informing a group that they are participating in a pilot session allows strategies to be trialled and evaluated. It also provides a first-hand experience of student reactions and their levels of participation, and learning from these is important to ensuring that the final published programme tackles a potentially challenging issue in a constructive way. This should ensure that the final published programme will enable the students to participate and engage with ease and in a comfortable manner; the additional benefit of this is that their positive experience will hopefully encourage the school to book onto the programme again.

Regardless of advancements in technology, people appreciate an awareness of how ideas and objects originated and developed. The process of transactions may have changed, but the nature and rationale for them are still the same. Monetary collections are ideally placed to support students in understanding how to efficiently use money and make informed decisions by considering historical examples. They provide an opportunity to create a learning experience that is memorable and delivered in a contextualized manner with direct references to items in the collection. This will ensure that students can appreciate the role that money has played, and continues to play, in society, enabling them to feel confident about making financial decisions in their futures. Promoting such a longitudinal and valuable learning outcome will encourage teachers to explore the opportunities available in museum education programmes. The variety of sessions available in the Citi Money Gallery education programme should enable a quick response to the question, 'Are coins small and boring?' By providing students with hands on opportunities and the chance to explore and develop their own knowledge in a professional environment, the coins should be seen as a springboard for exploring ideas, and from this comes the intrigue to develop their knowledge even further.

Received:11 October 2014

Finally Accepted: 6 March 2015

\section{Notes}

1 The Money Charity (2014) January Debt Statistics 2014 [Online] http://themoneycharity. org.uk/media/Debt-Stats-Full-January-2014.pdf (Accessed 4 February 2014)

\section{Websites referenced}

Collections Trust, (2009), What is Revisiting Collections? http://www.collectionslink.org.uk (Accessed 15 January 2014)

Crawford, M. L., (2001), Teaching Contextually https://www.cord.org/uploadedfiles/Teaching\%20 Contextually\%20(Crawford).pdf (Accessed 4 February 2014)

Cribb, J (2001) The HSBCMoney Gallery at the British Museum: Access to excellence ICOMON www.icomon.org/file download/128/Cribb+1999.pdf (Accessed 29 January 2014)

Department for Education (2013) Improving the Spiritual, Moral, Social and Cultural development of pupils https://www.gov.uk/government/uploads/system/uploads/attachment data/ file/268826/dept advice template smscadvicenov13.pdf (Accessed 12 March 2014)

Empson, W. (1932) Homage to the British Museum http://www.britishmuseum.org/explore/ highlights/article index/h/homage to the british museum b.aspx (Accessed 20 March 2014)

Learning Outside The Classroom (2011) Manifestowww.lotc.org.uk/wp-content/uploads/2011/03/ G1.-LOtC-Manifesto.pdf (Accessed 4 February 2014) 
Lusardi, A., Mitchell, O. S. and Curto, V. (2009) Financial Literacy Among the Young: Evidence and Implications for Consumer Policy http://www.nber.org/papers/w15352 (Accessed 29 January 2014)

Ofsted (2008) Learning outside the classroom http://www.ofsted.gov.uk/resources/learningoutside-classroom (Accessed 4 February 2014)

Orna-Ornstein, J., (2003), Coins are small and boring: The importance of an education programme for a numismatic collection [Online] www.icomon.org/file download/105/OrnaOrnstein+2001.pdf (Accessed 29 January 2014)

\section{References}

Anderson, D., (1999), A Common Wealth: Museums in the Learning Age, a Report to the Department for Culture, Media and Sport, London: Stationery Office

Bellamy, K. and Oppenheim, C., (eds), (2009), Learning to Live: Museums, young people and education http://www.nationalmuseums.org.uk/media/documents/publications/ learning to live.pdf (4 February 2014)

Berry, R. Q., Reed, P. A., Ritz, J. M., Lin, C. Y., Hsiung, S. and Frazier, W., (2005), 'STEM initiatives: Stimulating students to improve science and mathematics achievement', The Technology Teacher 23-29.

Blair, A., (2008), Inquiry teaching Mathematics Teaching incorporating Micromath 211 pp 8-11

Cardwell, M., Clark, L. and Meldrum, C. eds., (2004), Psychology, London: Collins

Clark, R. L. and d'Ambrosio, M. B., (2003), 'Ignorance Is Not Bliss: The Importance Of Financial Education', TIAA-CREF Institute Research Dialogue 78, 1-14. https://www. tiaa-crefinstitute.org/public/pdf/institute/research/dialogue/78.pdf. (Accessed 29 January 2014)

Duclos-Orsello, E. A., (2013), 'Shared Authority: The Key to Museum Education as Social Change', Journal of Museum Education, 38(2) 121-128 http://museumeducation.info/ wp-content/uploads/2013/07/s2.pdf (Accessed 4 February 2014)

Dudley, S., (2010), Museum Materialities: objects, engagements, interpretations Routledge: London and New York

Gosden, C., (2005), 'What do objects want?', Journal of Archaeological Method and Theory 12 (3) 193-221.

Hardy, G., (2008), 'A Creativity Taxonomy' Mathematics Teaching incorporating Micromath, 211, 26-29.

Harris, M. and Butterworth, G., (2004), Developmental Psychology, Hove: Psychology Press Ltd.

Hein, G. E., (1998), Learning in the Museum, Routledge: London

McCormick, M. A., (2009), 'The Effectiveness of Youth Financial Education: A Review of the Literature', Journal of Financial Counseling and Planning, 20 (1) 70-83.

Lewis, B. N., (1980), 'The Museum as an Educational Facility', Museums Journal, 80 (3) 151-55. 
Lyons, A. C. and Neelakantan, U., (2008), 'Potential and Pitfalls of Applying Theory to the Practice of Financial Education', The Journal of Consumer Affairs, 42 (1) 106-112.

Museums Association, (2005), Collections for the Future, Museums Association: London.

Nomikou, E. in Fritsch, J., (ed), (2011), Museum Gallery Interpretation and Material Culture, Routledge: Oxford.

Orna-Ornstein, J., (ed), (2001), Development and evaluation of the HSBC Money Gallery at the British Museum, Occasional Paper, London: British Museum.

Rebello, N. J., Cui, L., Bennet, A. G., Zollman, D. A. and Ozimek, D. J., (2007), 'Transfer of Learning in Problem Solving in the Context of Mathematics and Physics' Learning to solve complex, scientific problems 2 1-36

Thompson, S. (2008) Brain based learning EBSCO Research Starters 1-13

Wolf, B. and Wood, E., (2012), 'Integrating Scaffolding Experiences for Young Visitors', Journal of Museum Education, 37 (1) 29-38. http://museumeducation.info/wpcontent/uploads/2011/07/Integr_scaffold experiences.pdf. (Accessed 29 January 2014)

* Mieka Harris joined the British Museum in September 2012 following three years as Head of Key Stage 3 Mathematics in a high performing secondary school in Cambridgeshire. Alongside the role at the British Museum, Mieka lectures on the Secondary Mathematics PGCE course and the Subject Knowledge Enhancement course at the University of Bedfordshire. Prior to these, Mieka worked in the insurance industry as an underwriter. Mieka recently completed her MA in Education and holds a BSc in Economics and International Development.

Mieka Harris, Education Manager,

Citi Money Gallery

Department of Learning, Volunteers and Audiences

The British Museum

Great Russell Street, London WC1B 3DG

britishmuseum.org/money

+4402073238459

mharris@britishmuseum.org 